Annals of International Medical and Dental Research

E-ISSN: 2395-2822 | P-ISSN: 2395-2814

Vol-8, Issue-1 | January-February 2022

DOI: $10.53339 /$ aimdr.2022.8.1.12

Page no- 87-92 | Section- Research Article (Miscellaneous)

\title{
Assessment of Utility of Immunohistochemical Marker Prostein for Evaluation of Primary and Metastatic Prostatic Carcinomas
}

\author{
Ashwini Ramji ${ }^{1 *}$, Shanmugan C V ${ }^{2}$
}

\begin{abstract}
${ }^{1}$ Assistant Professor, Department of Pathology, PK Das Institute of Medical Sciences, Vaniamkulam, Ottapalam, Kerala, India.

Email: drashwiniwins@gmail.com

Orcid ID: 0000-0001-6078-9590

${ }^{2}$ Assistant Professor, Department of Medicine, PK Das Institute of Medical Sciences, Vaniamkulam, Ottapalam, Kerala, India.

Email: drcvshanmughan@gmail.com

Orcid ID: 0000-0002-1098-2146
\end{abstract}

*Corresponding author

Received: 05 October 2021

Revised: 08 November 2021

Accepted: 17 November 2021

Published: 22 December 2021

\begin{abstract}
Background: To assess utility of immunohistochemical marker prostein for evaluation of primary and metastatic prostatic carcinomas. Methods: Fiftysix samples of clinically suspected carcinoma prostate was included. Immunohistochemistry (IHC) was performed for assessment of Prostein (P501S). The intensity of positivity was scored from 0 to 3 as follows: score 0 = non-stained; score 1 = weak; score 2 = moderate; and score $3=$ strong. The percentage of positively stained cells for each staining intensity was estimated in the respective lesions. Results: Age group 18-28 years comprised of 6 patients, 28-38 years had 12, 38- 48 years had 16 and $>48$ years had 22 cases. Type of cases were normal prostatic epithelium in 11, benign prostate hyperplasia in 23 , HGPIN in 10 , primary prostatic adenocarcinoma in 7 and metastatic prostatic adenocarcinoma in 5 cases. Prostein expression was seen in $100 \%$ in normal prostatic epithelium with intensity score of 1.8-2.1, benign prostate hyperplasia having 2-2.7, HGPIN with 2-2.3, primary prostatic adenocarcinoma having 1-1.6 and metastatic prostatic adenocarcinoma with 0.8-1.4 intensity score. Conclusion: Prostein is a new prostate specific marker which showed $100 \%$ sensitivity and specificity to identify normal and prostatic lesions.
\end{abstract}

Keywords:- Benign prostate hyperplasia, Prostein, Primary prostatic adenocarcinoma.

\section{INTRODUCTION}

Prostate cancer is the second most frequently diagnosed cancer as well as the sixth leading cause of death in males with increasing incidence worldwide. Several Indian registries have revealed an increasing trend in the incidence of prostate cancer and the mean annual percentage change has ranged from 0.14 to $8.6 \%$.[1]
In the earlier stage of advanced prostate cancer, malignant cells shed from the primary tumor migrate locally, invade blood vessels, and may disperse widely in the body.[2] Prostate cancer cells that spread out of the prostate show an exquisite tropism for the bone. In one autopsy study, approximately $90.1 \%$ of the men who had died with hematogenous metastases of prostate cancer were diagnosed with bone metastases.[]ㅡ Based on the "seed and soil" theory proposed by Paget, the growth of tumor 
Annals of International Medical and Dental Research E-ISSN: 2395-2822 | P-ISSN: 2395-2814 Vol-8, Issue-1 | January-February 2022 DOI: $10.53339 /$ aimdr.2022.8.1.12

Page no- 87-92 | Section- Research Article (Miscellaneous)

foci tends to be the direct result of a specific organ's microenvironment. Prostate cells ("seeds") in the bloodstream need to settle in an appropriate "soil", thus they preferentially migrate to bone. These malignant cells invade and eventually proliferate in the bones of the axial skeleton, such as the ribs, pelvis, and spine, where red marrow is most abundant. [4]

The diagnosis of prostatic adenocarcinoma on histopathology depends on architectural and cytomorphological features supported by immunohistochemistry (IHC).[5] The utility of IHC in prostate cancer is primarily for confirming the diagnosis of carcinoma in biopsy material containing atypical glands. In addition, IHC helps confirm the prostatic origin of the tumor in the primary or metastatic setting of high-grade prostatic adenocarcinoma and differentiate that from non-prostatic carcinomas. The new IHC markers include prostein (P501S) and NKX3.6] Prostein (P501S) is a prostate-specific 553 amino acid protein identified by complementary DNA (cDNA) subtraction. It is an organ-specific marker for benign and malignant prostatic epithelial cells. Its expression is restricted to prostatic tissues and unrelated to Gleason grade. It shows characteristic diffuse granular cytoplasmic (Golgi) staining and provides an additional valuable IHC marker for detection of metastatic prostatic carcinoma.7] Considering thus, the present study was undertaken with the aim to assess diagnostic utility of immunohistochemical marker prostein for evaluation of primary and metastatic prostatic carcinomas.

\section{MATERIAL AND METHODS}

A total of fifty- six samples of clinically suspected carcinoma prostate was included in the study. The study was approved from institutional ethical clearance committee.

The samples were obtained using both primary (core biopsy, transurethral resection of the prostate [TURP] and radical cystoprostatectomy) and metastatic sites. Data such as demographic and clinical were retrieved. Ultrasound (US) or magnetic resonance imaging (MRI) data and serum PSA values were obtained. Immunohistochemistry (IHC) was performed for assessment of Prostein (P501S). The intensity of positivity was scored from 0 to 3 as follows: score $0=$ non-stained; score $1=$ weak; score 2 = moderate; and score 3 = strong. The percentage of positively stained cells for each staining intensity was estimated in the respective lesions. Results of the study was clubbed together and were subjected for statistical inference. $P$ value less than 0.05 was considered significant.

\section{RESULTS}

Age group 18-28 years comprised of 6 patients, $28-38$ years had $12,38-48$ years had 16 and $>48$ years had 22 cases.

Type of cases were normal prostatic epithelium in 11, benign prostate hyperplasia in 23 , HGPIN in 10, primary prostatic adenocarcinoma in 7 and metastatic prostatic adenocarcinoma in 5 cases.

Prostein expression was seen in $100 \%$ in normal prostatic epithelium with intensity score of 1.82.1, benign prostate hyperplasia having 2-2.7, HGPIN with 2-2.3, primary prostatic adenocarcinoma having 1-1.6 and metastatic 
Annals of International Medical and Dental Research

E-ISSN: 2395-2822 | P-ISSN: 2395-2814

Vol-8, Issue-1 | January-February 2022

DOI: $10.53339 /$ aimdr.2022.8.1.12

Page no- 87-92 | Section- Research Article (Miscellaneous)

prostatic adenocarcinoma with 0.8-1.4 intensity

score.

Table 1: Distribution of patients based on age

\begin{tabular}{|l|l|l|}
\hline Age group (Years) & Number & P value \\
\hline $18-28$ & 6 & $<0.05$ \\
\cline { 1 - 2 } $28-38$ & 12 & \\
\cline { 1 - 2 }-48 & 16 & \\
\cline { 1 - 2 } & 22 & \\
\hline
\end{tabular}

Table 2: Type of cases

\begin{tabular}{|l|l|l|}
\hline Type of cases & Number & P value \\
\hline Normal prostatic epithelium & 11 & $<0.05$ \\
\cline { 1 - 2 } Benign prostate hyperplasia & 23 & \\
\cline { 1 - 2 } HGPIN & 10 \\
\hline Primary prostatic adenocarcinoma & 7 & \\
\cline { 1 - 2 } Metastatic prostatic adenocarcinoma & 5 & \\
\hline
\end{tabular}

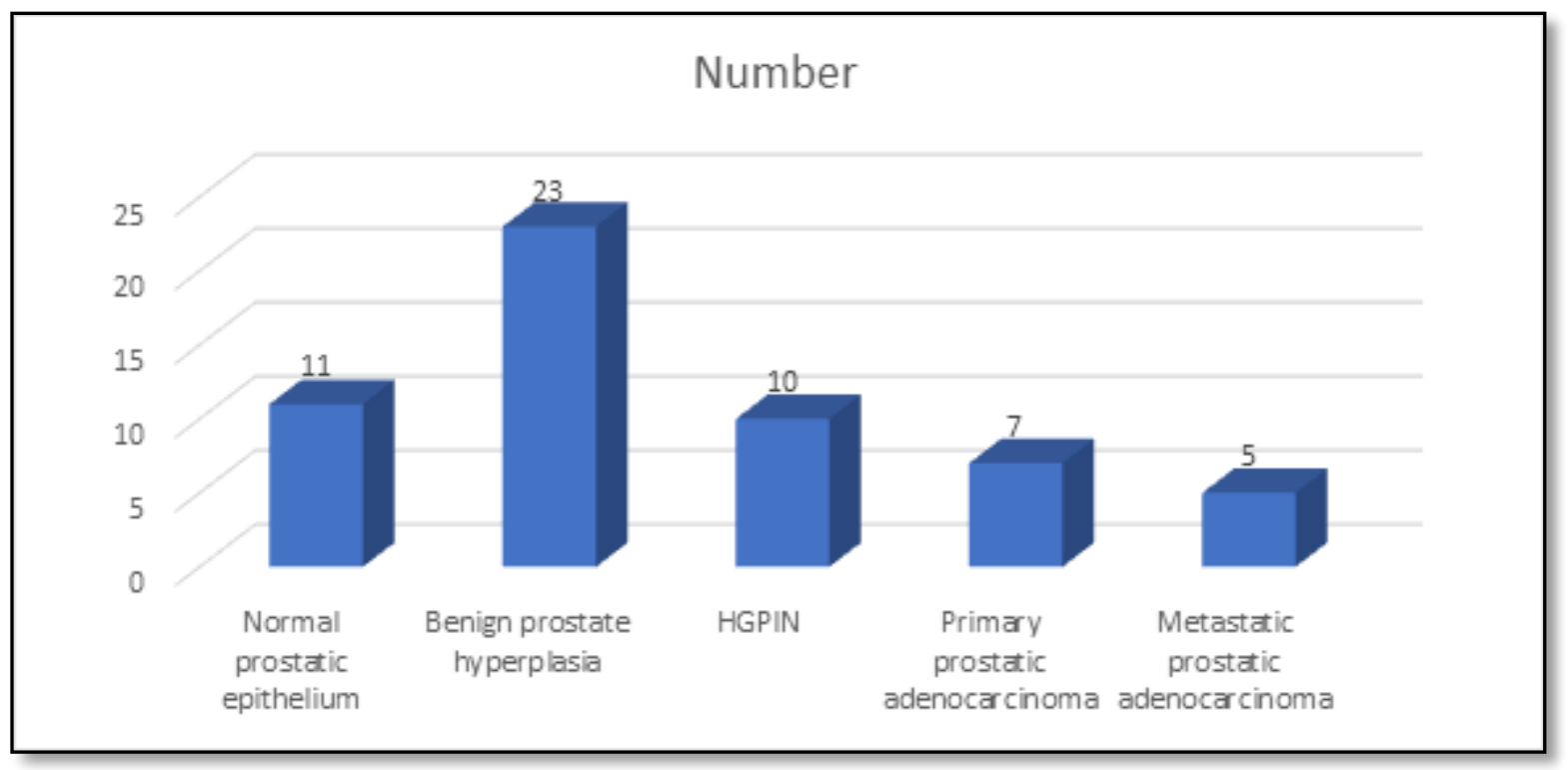

Figure 1: Type of cases

Table 3: Expression of Prostein in various lesions

\begin{tabular}{|l|l|l|}
\hline Type of cases & Prostein & Intensity score \\
\hline Normal prostatic epithelium & $100 \%$ & $1.8-2.1$ \\
\hline Benign prostate hyperplasia & $100 \%$ & $2-2.7$ \\
\hline HGPIN & $100 \%$ & $2-2.3$ \\
\hline
\end{tabular}


Annals of International Medical and Dental Research

E-ISSN: 2395-2822 | P-ISSN: 2395-2814

Vol-8, Issue-1 | January-February 2022

DOI: $10.53339 /$ aimdr.2022.8.1.12

Page no- 87-92 | Section- Research Article (Miscellaneous)

\begin{tabular}{|l|l|l|}
\hline Primary prostatic adenocarcinoma & $100 \%$ & $1-1.6$ \\
\hline Metastatic prostatic adenocarcinoma & $100 \%$ & $0.8-1.4$ \\
\hline
\end{tabular}

\section{DISCUSSION}

During metastatic bone disease, the interaction between tumor cells with osteoblasts and osteoclasts elicits an osteolytic, osteoblastic, or mixed bone response. A purely osteolytic response is characterized by the destruction of normal bone attributable to the occurrence of osteoblast inactivation as well as osteoclast recruitment and activation in the tumor-bone microenvironment.[8] Osteolytic lesions are characterized by soft sections of damaged bone resulting from an osteolytic response that can cause bone pain and fractures. A purely osteoblastic response refers to the deposition of new bone due to the new bone formation which is not preceded by bone resorption. [9] Osteoblastic lesions, resulting from an osteoblastic response, are depositions of mineralized or calcified bone into the tissue lesions. A mixed bone response is a condition whereby an individual experiences a combination of both osteolytic and osteoblastic components.[10] The present study assessed diagnostic utility of immunohistochemical marker prostein for evaluation of primary and metastatic prostatic carcinomas.

Our study revealed that Age group 18-28 years comprised of 7 patients, $28-38$ years had 12 , 3848 years had 16 and $>48$ years had 22 cases. Garudadri et al,[11] studied the expression of prostein in normal, benign, and malignant (primary and metastatic) lesions with particular emphasis on its utility in the differential diagnosis of poorly differentiated and metastatic prostatic adenocarcinoma along with a standard panel of IHC markers. All samples from patients with clinically suspected carcinoma prostate from both primary and metastatic sites were included in the study. Prostein showed a $100 \%$ sensitivity and specificity to identify normal prostatic epithelium, benign and premalignant lesions, and prostatic adenocarcinoma. Prostein showed a specificity of $100 \%$ in differentiating prostatic carcinoma from poorly differentiated urothelial carcinoma and in differentiating metastatic prostatic carcinoma from adenocarcinoma of non-prostatic origin.

Our results showed that type of cases were normal prostatic epithelium in 11, benign prostate hyperplasia in 23, HGPIN in 10, primary prostatic adenocarcinoma in 7 and metastatic prostatic adenocarcinoma in 5 cases. Yi et al,[12] studied the expression of PSA and prostein in 54 metastatic prostatic carcinomas (30 lymph nodes and 24 distant metastasis), where PSA was expressed in $87 \%$ and prostein in $86.7 \%$ of samples. The mechanisms responsible for the diminished expression of P501S in metastatic prostatic carcinomas are unknown but could be similar to those for PSA.

We observed that Prostein expression was seen in $100 \%$ in normal prostatic epithelium with intensity score of 1.8-2.1, benign prostate hyperplasia having 2-2.7, HGPIN with 2-2.3, primary prostatic adenocarcinoma having 1-1.6 and metastatic prostatic adenocarcinoma with 0.8-1.4 intensity score. Queisser et al,[13] showed sensitivity of PSA, PSMA, and androgen receptor to be $97 \%, 94 \%$, and $91 \%$, respectively 
Annals of International Medical and Dental Research

E-ISSN: 2395-2822 | P-ISSN: 2395-2814

Vol-8, Issue-1 | January-February 2022

DOI: 10.53339/aimdr.2022.8.1.12

Page no- 87-92 | Section- Research Article (Miscellaneous)

and concluded that sensitivity can be increased up to $98 \%$ to $100 \%$ with the combined use of PSMA and P501S. Srinivasan and Parwani,[14] studied 132 patients with high-grade UC and 23 patients of prostatic carcinoma with p63 and P501S. They observed that p63+/P501Simmunoprofile had $90 \%$ sensitivity and $100 \%$ specificity for UC and p63-/P501S+ immunoprofile had $96 \%$ sensitivity and 100\% specificity for prostatic carcinoma. Chuang et

\section{REFERENCES}

1. Lalitha K, Suman G, Pruthvish S, Mathew A, Murthy NS. Estimation of time trends of incidence of prostate cancer an Indian scenario. Asian Pac J Cancer Prev 2012;13:6245 50. https://doi.org/10.7314/apjcp.2012.13.12.6245

2. Epstein JI, Egevad L, Humphrey PA, Montironi R; Members of the ISUP Immunohistochemistry in Diagnostic Urologic Pathology Group. Best practices recommendations in the application of immunohistochemistry in the prostate: report from the International Society of Urologic Pathology consensus conference. Am J Surg Pathol. 2014;38(8):e6-e19.

doi: 10.1097/PAS.0000000000000238.

3. Adisa JO, Egbujo EC, Ibrahim B, Musa B, Madukwe J. Expression of some selected cytokeratins and Ki67 protein in prostatic tumor: can these be used as tumor markers. Pan Afr Med J. 2015;20:46. doi:10.11604/pamj.2015.20.46.3926

4. Kuroda N. Application of combined immunohistochemical panel of AMACR(P504S)/p63 cocktail, cytokeratin 5 and D2 40 to atypical glands in prostatic needle biopsy. Malaysian J Pathol. 2014;36:169 73.

5. Xu J, Kalos M, Stolk JA, Zasloff EJ, Zhang X, Houghton RL, et al. Identification and characterization of prostein, a novel prostate specific protein. Cancer Res. 2001;61:1563 8.

6. Humphrey PA, Moch H, Cubilla AL, Ulbright TM, Reuter VE. The 2016 WHO Classification of Tumours of the Urinary System and Male Genital Organs-Part B: Prostate and Bladder Tumours. Eur Urol. 2016 Jul;70(1):106-119. doi: 10.1016/j.eururo.2016.02.028. al,[15] observed that the sensitivity for labeling prostatic cancers for PSA, p501S, PSMA, and NKX3.1 was $97.4 \%, 100 \%, 92.1 \%$, and $94.7 \%$, respectively.

\section{CONCLUSIONS}

Prostein is a new prostate specific marker which showed $100 \%$ sensitivity and specificity to identify normal and prostatic lesions.

7. Madani SH, Ameli S, Khazaei S, Kanani M, Izadi B. Frequency of Ki-67 (MIB-1) and P53 expressions among patients with prostate cancer. Indian J Pathol Microbiol. 2011;54(4):688-91. doi: 10.4103/03774929.91492.

8. Morgan TM, Welty CJ, Vakar-Lopez F, Lin DW, Wright JL. Ductal adenocarcinoma of the prostate: increased mortality risk and decreased serum prostate specific antigen. J Urol. 2010;184(6):23032307. doi:10.1016/j.juro.2010.08.017

9. Rashed HE, Kateb MI, Ragab A, Shaker SS. Evaluation of minimal prostate cancer in needle biopsy specimens using AMACR (P5045), p63 and ki67. Life Sci J 2012;9:12 21.

10. Grignon DJ, Caplan R, Sarkar FH, Lawton CA, Hammond EH, Pilepich MV, et al. p53 status and prognosis of locally advanced prostatic adenocarcinoma: A study based on RTOG 8610. J Natl Cancer Inst 1997;89:158 65. https://dx.doi.org/10.4161\%2Fcc. 22852

11. Garudadri G, Rao BV, Sundaram C, Fonseca D, Murthy SS, Sharma R, Rao TS. Diagnostic utility of immunohistochemical marker prostein for evaluation of primary and metastatic prostatic carcinomas. Indian J Pathol Microbiol. 2020;63(Supplement):S18-S24. doi: 10.4103/IJPM.IJPM_852_18.

12. Yin M, Dhir R, Parwani AV. Diagnostic utility of p501s (prostein) in comparison to prostate specific antigen (PSA) for the detection of metastatic prostatic adenocarcinoma. Diagn Pathol. 2007;2:41. doi:10.1186/1746-1596-2-41

13. Queisser A, Hagedorn SA, Braun M, Vogel W, Duensing S, Perner S. Comparison of different prostatic markers in lymph node and distant 
Annals of International Medical and Dental Research

E-ISSN: 2395-2822 | P-ISSN: 2395-2814

Vol-8, Issue-1 | January-February 2022

DOI: $10.53339 /$ aimdr.2022.8.1.12

Page no- 87-92 | Section- Research Article (Miscellaneous)

metastases of prostate cancer. Mod Pathol. 2015;28(1):138-45. doi: 10.1038/modpathol.2014.77.

14. Srinivasan M, Parwani AV. Diagnostic utility of p63/P501S double sequential immunohistochemical staining in differentiating urothelial carcinoma from prostate carcinoma. Diagn Pathol. 2011;6:67. doi:10.1186/1746-1596-6-67

15. Chuang AY, DeMarzo AM, Veltri RW, Sharma RB, Bieberich CJ, Epstein JI. Immunohistochemical differentiation of high-grade prostate carcinoma from urothelial carcinoma. Am J Surg Pathol. 2007;31(8):1246-55. doi: 10.1097/PAS.0b013e31802f5d33.

Source of Support: Nil, Conflict of Interest: None declared 